\title{
Miraculous recovery after severe coronavirus disease-19 in old age patient: A rare case Report
}

\author{
Madhulika Dubey ${ }^{1}$, Mohd. Mustahsin², Garima Singh ${ }^{3}$ \\ From ${ }^{1}$ Consultant, ${ }^{2}$ Consultant and Head, Department of Anesthesiology and Critical Care, Critical Care Unit, ${ }^{3}$ Senior Resident, Department of \\ Anesthesiology and Critical Care, Era's Lucknow Medical College and Hospital, Lucknow, Uttar Pradesh, India
}

\begin{abstract}
A novel severe acute respiratory syndrome coronavirus 2 led to an ongoing coronavirus disease (COVID)-19 pandemic since December 2019. It has affected all age groups; however, older adults are particularly susceptible to the virus and develop severe symptoms, and frequently require critical care admissions. They often require long-term home-based care and multidisciplinary rehabilitation programs. Here, we report a case of complete clinical recovery of a 74-year-old female with no post-COVID sequelae despite severe acute respiratory distress syndrome, multiple comorbidities, and the need for invasive mechanical ventilation. We believe that this case report can further guide the physicians to manage such critical cases.
\end{abstract}

Key words: Coronavirus disease-19, Novel severe acute respiratory syndrome coronavirus 2, Older adults, Rehabilitation, Tele-monitoring

$\mathrm{S}$ evere acute respiratory syndrome coronavirus 2 (SARSCoV2) was identified as the etiological factor of pneumonia cases that started in Wuhan city, Hubei province, China, in December 2019 [1,2]. Coronavirus disease (COVID)-19 affects individuals of all ages. However, those having comorbidities such as asthma, diabetes, hypertension, cancer, cardiovascular abnormalities, older adults, and immunocompromised are affected more severely [3]. Older adults frequently require intensive care unit (ICU) care and have a significantly higher mortality rate [4]. Moreover, COVID-19 survivors develop long COVID symptoms such as fatigue, muscle weakness, sleep difficulties, anxiety, depression, and post-ICU syndrome [5]. There is a paucity of literature on complete recovery to premorbid state in old age COVID pneumonia patients with multiple comorbidities. We hereby report a case of a 74-year-old female with severe COVID-19 who was successfully managed and recovered completely despite the various challenges faced during the management.

\section{CASE REPORT}

A 74-year-old female was referred to our COVID center from a private hospital with chief complaints of fever, cough, and breathlessness for 5 days. Her nasopharyngeal swab for

\section{Access this article online}

Received - 17 March 2021

Initial Review - 02 April 2021

Accepted - 06 April 2021

DOI: $10.32677 /$ IJCR.2021.v07.i04.008
SARS-CoV-2 reverse transcription-polymerase chain reaction (RT-PCR) was positive. She was a known case of type-2 diabetes mellitus for 10 years and hypertension for 8 years and on treatment.

On examination, her temperature was $100.6^{\circ} \mathrm{F}$, heart rate was $110 / \mathrm{min}$, blood pressure was $146 / 89 \mathrm{mmHg}$, respiratory rate (RR) was 36 breaths/minute, was $\mathrm{SpO}_{2}$ was $79 \%$ on room air which improved to $91 \%$ on $15 \mathrm{~L} / \mathrm{min}$ oxygen through a non-rebreathing mask. The patient was categorized as severe COVID-19 according to the World Health Organization classification [6].

She was immediately placed on high-flow nasal cannula with $\mathrm{FiO}_{2} 1.0$ and flow of $60 \mathrm{~L} / \mathrm{min}$. Arterial blood gas test showed a $\mathrm{pH}$ of $7.42, \mathrm{pCO}_{2}$ of $31, \mathrm{paO}_{2}$ of 46 , and $\mathrm{HCO}_{3}$ of 20.1. Chest radiograph showed showing bilateral patchy areas of consolidation (Fig. 1a). High resolution computed tomography (CT) chest showed multiple ground-glass opacities in bilateral lung fields (CT severity score 17/25).

Blood investigation reports were as follows: Hemoglobin-10.1 g/dl, total leukocyte count-8800 cells $/ \mathrm{mm}^{3}$, platelets- 200,000 , urea- $31.8 \mathrm{mg} / \mathrm{dl}$, creatinine- $1.10 \mathrm{mg} / \mathrm{dl}$, bilirubin- $0.40 \mathrm{mg} / \mathrm{dl}$, serum glutamic-oxaloacetic transaminase-148 $\mathrm{U} / \mathrm{L}$, serum glutamic-pyruvic transaminase-72 U/L, albumin-2.6g/dl, C-reactive protein $>90.0 \mathrm{mg} / \mathrm{L}$, ferritin- $718 \mathrm{ng} / \mathrm{ml}$, D-dimer $1.8 \mathrm{mg} / \mathrm{L}$, and interleukin-6-78 pg/ml.

Thepatientwasstarted on remdesivir, meropenem, doxycycline, dexamethasone, ivermectin, and low molecular weight heparin.

Correspondence to: Dr. Mohd Mustahsin, Eras Lucknow Medical College and Hospital, Lucknow, Uttar Pradesh, India - 226003.

E-mail: mustahsin.malik@gmail.com

(C) 2021 Creative Commons Attribution-NonCommercial 4.0 International License (CC BY-NC-ND 4.0). 


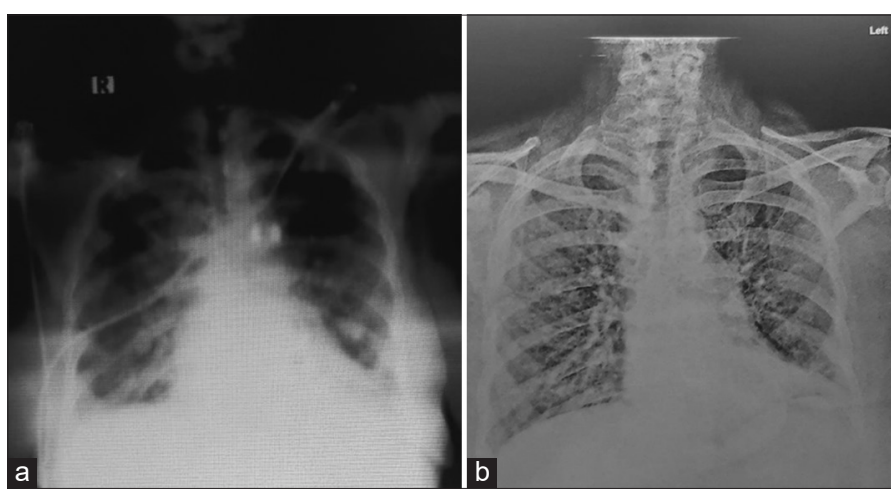

Figure 1: (a) Anteroposterior view of the chest radiograph on admission showing bilateral patchy areas of consolidation; (b) posteroanterior view of the chest radiograph after 2 months of hospital discharge showing ground-glass opacities

The patient was encouraged for awake self-proning. However, on the $4^{\text {th }}$ day of admission, the patient developed respiratory distress (RR 46/min.) and a fall in saturation $\left(\mathrm{SpO}_{2}-80 \%\right.$ on $\left.\mathrm{FiO}_{2} 1.0\right)$. She was intubated and placed on mechanical ventilation (PRVC mode with PEEP of $12 \mathrm{~cm} \mathrm{H}_{2} \mathrm{O}$, RR 28/min, tidal volume $330 \mathrm{ml}$, and $\mathrm{FiO}_{2} 1.0$ ). The patient was immediately proned for prone ventilation. After proning, the $\mathrm{SpO}_{2}$ improved to $92 \%$. $\mathrm{FiO}_{2}$ was gradually decreased to 0.7 over $12 \mathrm{~h}$. The patient underwent three sessions of proning, each session lasting for approximately $16 \mathrm{~h}$. After three sessions of proning, she was able to maintain saturation even in a supine position. After a successful spontaneous breath trial (SBT), she was extubated to non-invasive ventilation (NIV). Chest physiotherapy, incentive spirometry, mobilization, and awake self-proning were continued.

She was gradually weaned off from NIV and was discharged after ten days of hospitalization when her RT-PCR report for COVID-19 came negative. She was discharged on nasal prong with oxygen support of $3 \mathrm{~L} / \mathrm{min}$. The patient's son was a doctor and necessary arrangements were made at home for her medical care. They were continuously in contact with the critical care team through teleconsultation. Aggressive physiotherapy and mobilization were continued at home. Gradually, her oxygen support weaned off and she was able to maintain saturation on room air after 12 days of hospital discharge. After that, she was able to perform daily routine work independently. Chest X-ray repeated after 2 months showed post-COVID changes (Fig. 1b), but clinically she was not having any post COVID complaints. The patient was followed up for 6 months. She is currently leading a normal life with no post-COVID sequelae and no postICU syndrome.

\section{DISCUSSION}

This was an interesting case where timely and protocolized ICU management and good post-ICU care with teleconsultation by the intensivist resulted in complete recovery from severe COVID-19 pneumonia in a 74-year-old female with multiple comorbidities.

The human population is trending towards a society with a higher proportion of the old age population. Hence, a better understanding of the issues in this age group is important, particularly during this pandemic time. The elderly, particularly the ones with underlying diseases, are more vulnerable for COVID-19 [3,4]. A study of 1099 patients with SARS-CoV-2 pneumonia found that $15.1 \%$ of the patients were aged 60 years and above, $27.0 \%$ of whom were severe [7]. In developed countries, older adults infected with COVID-19 had a mortality rate of $83.7 \%$ for $>70$ years and $16.2 \%$ in patients younger than 69 years [8]. Thus, advanced age is a poor prognostic factor for SARSCoV2, especially with underlying co-morbid conditions.

The comorbidities and their adverse effects are the main risk factors for the development of pneumonia in the elderly. The respiratory functions and respiratory muscle strength decreases with age. The immunity of the body also decreases with age, making the person more susceptible to infection, malignancy, and delayed recovery. The virulence and the viral load also play an important factor.

Our patient was having severe COVID-19 pneumonia and multiple comorbidities. The patient underwent multiple sessions of awake proning throughout the day. Better outcome has been demonstrated in different studies in patients undergoing awake self-proning. UK Intensive Care Society recommends awake prone positioning to become standard of care for suspected or confirmed COVID-19 in patients requiring a $\mathrm{FiO}_{2} \geq 28 \%$ [9]. Our patient was intubated in view of respiratory distress and she was immediately proned. She underwent three sessions of proning, each session lasting for about $16 \mathrm{~h}$. According to the data provided by the Istituto Superiore di Sanità, acute respiratory distress syndrome (ARDS) was observed in the majority of patients ( $96.1 \%$ of cases) dying in hospital [10]. The beneficial effect of proning in ARDS has been demonstrated in the PROSEVA trial which showed 28 days mortality benefit in the prone group $(16.0 \%$ in the prone group and $32.8 \%$ in the supine group $[p<0.001]$ ) [11].

After 3 days of invasive mechanical ventilation, our patient was extubated to NIV. The American College of Chest Physicians/ American Thoracic Society guidelines recommend preventive NIV after extubation for patients at high risk for extubation failure who are on mechanical ventilation for more than $24 \mathrm{~h}$ and have passed a SBT [12]. The patient was gradually weaned off of NIV. Although the chest X-ray did not show complete clearance of the infiltrates but the clinical condition of the patient was stable, and hence, she was discharged after 10 days of hospitalization. A study by Grutters et al. showed that after the early discharge of COVID-19 patients, home telemonitoring is a safe, cost-effective, and patient-friendly measure. It also decreases the duration of hospitalization, particularly in patients who require home oxygen therapy [13].

Huang et al. conducted an ambidirectional cohort study of patients with confirmed COVID-19 who had been discharged from Jin Yin-tan Hospital (Wuhan, China) between January 7, 2020, and May 29, 2020. A total of 1733 of 2469 discharged patients with COVID-19 were enrolled. They found that six months after acute infection, COVID-19 survivors usually develop fatigue, muscle weakness, sleep difficulties, anxiety, or depression [14]. 
However, on 6 months follow-up, no such complication occurred in our patient and she is now leading a normal and healthy life.

\section{CONCLUSION}

To the best of our knowledge, this is the first case report of complete recovery in a patient with $>70$ years of age who presented with severe COVID-19 pneumonia leading to severe ARDS who was successfully treated by a multidisciplinary approach. Timely intubation, early proning, extubation to NIV, early mobilization, early starting of rehabilitation programs, early discharge from ICU to home care, and teleconsultation by the intensivist are cornerstones of critical care management in such cases.

\section{REFERENCES}

1. Zhu N, Zhang D, Wang W, Li X, Yang B, Song J, et al. China novel Coronavirus investigating and research team. A novel coronavirus from patients with pneumonia in China, 2019. N Engl J Med 2020;382:727-33.

2. Bhimraj A, Morgan RL, Shumaker AH, Lavergne V, Baden L, Cheng VC, et al. Infectious diseases society of America guidelines on the treatment and management of patients with COVID-19. Clin Infect Dis 2020; 2020:ciaa478.

3. Liu K, Chen Y, Lin R, Han K. Clinical features of COVID-19 in elderly patients: A comparison with young and middle-aged patients. J Infect 2020;80:e14-8.

4. Guan WJ, Ni ZY, Hu Y, Liang WH, Ou CQ, He JX, et al. Clinical characteristics of Coronavirus disease 2019 in China. N Engl J Med 2020;382:1708-20.

5. Greenhalgh T, Knight M, A'Court C, Buxton M, Husain L. Management of post-acute COVID-19 in primary care. BMJ 2020;370:m3026.

6. World Health Organization. Clinical Management of COVID-19: Interim Guidance, 27 May 2020. Geneva: World Health Organization; 2020. Available from: https://www.apps.who.int/iris/handle/10665/332196. [Last accessed on 2021 Mar 21].

7. Huang C, Wang Y, Li X, Ren L, Zhao J, Hu Y, et al. Clinical features of patients infected with 2019 novel Coronavirus in Wuhan, China. Lancet 2020;395:497-506

8. Chen N, Zhou M, Dong X, Qu J, Gong F, Han Y, et al. Epidemiological and clinical characteristics of 99 cases of 2019 novel coronavirus pneumonia in Wuhan, China: A descriptive study. Lancet 2020;395:507-13.

9. Bamford P, Bentley A, Dean J, Whitmore D, Wilson-Baig N. ICS Guidance for Prone Positioning of the Conscious COVID Patient; 2020. Available from: https://www.icmanaesthesiacovid-19.org/news/ics-guidance-forprone-positioning-of-the-conscious-covid-patient-2020. [Last accessed on 2021 Mar 04].

10. Characteristics of SARS-CoV-2 Patients Dying in Italy Report Based; 2020. Available from: https://www.epicentro.iss.it covid-2019_2_april_2020. [Last accessed on 2021 Mar 10].

11. Guérin C, Reignier J, Richard JC, Beuret P, Gacouin A, Boulain T, et al. Prone positioning in severe acute respiratory distress syndrome. N Engl J Med 2013;368:2159-68.

12. Ouellette DR, Patel S, Girard TD, Morris PE, Schmidt GA, Truwit JD, et al. Liberation from mechanical ventilation in critically Ill Adults: An official american college of chest physicians/American thoracic society clinical practice guideline: Inspiratory pressure augmentation during spontaneous breathing trials, Protocols minimizing sedation, and noninvasive ventilation immediately after extubation. Chest 2017;151:166-80.

13. Grutters LA, Majoor KI, Mattern ES, Hardeman JA, van Swol CF, Vorselaars AD. Home telemonitoring makes early hospital discharge of COVID-19 patients possible. J Am Med Inform Assoc 2020;27:1825-7.

14. Huang C, Huang L, Wang Y, Li X, Ren L, Gu X, et al. 6-month consequences of COVID-19 in patients discharged from hospital: A cohort study. Lancet 2021;397:220-32.

Funding: None; Conflicts of Interest: None Stated.

How to cite this article: Dubey M, Mustahsin M, Singh G. Miraculous Recovery after Severe Coronavirus Disease-19 in Old Age Patient: A Rare Case Report. Indian J Case Reports. 2021;7(4):149-151. 